\title{
Fetal and Maternal Hormonal Response to Starvation in the Ewe
}

\author{
RICHARD L. SCHREINER, PHYLLIS A. NOLEN, PAULINE W. BONDERMAN, \\ HELEN C. MOOREHEAD, EDWIN L. GRESHAM, JAMES A. LEMONS, \\ AND MARILYN B. ESCOBEDO
}

Section of Neonatal-Perinatal Medicine, Department of Pediatrics, Indiana University School of Medicine, and the James Whitcomb Riley Hospital for Children, Indianapolis, Indiana, USA

\section{Summary}

Five ewes 90-130 days of gestation with chronically indwelling fetal catheters were studied. Blood samples were drawn each morning simultaneously from the maternal femoral artery, fetal femoral artery, and fetal umbilical vein. Total starvation was begun after blood samples had been drawn on the 3rd morning, but water was given ad libitum. The mean maternal arterial plasma glucose concentration before starvation $(73.4 \pm 31.0(S E M) \mathrm{mg} / 100 \mathrm{ml}$ plasma $\left.\mathrm{H}_{2} \mathrm{O}\right)$ fell to $54.8 \pm 5.2 \mathrm{mg} / 100 \mathrm{ml}(P<0.01)$ after $24 \mathrm{hr}$ of fasting and to $37.5 \pm 1.6 \mathrm{mg} / 100 \mathrm{ml}(P<0.001)$ by $72 \mathrm{hr}$ of fasting. The maternal arterial fructose concentration was low in both the fed $(2.9 \pm 0.4 \mathrm{mg} / 100 \mathrm{ml})$ and fasted states $(1.8 \pm 0.5$ $\mathrm{mg} / 100 \mathrm{ml}$, day 3 ). The maternal arterial insulin concentration fell early in fasting from a mean of $27.9 \pm 3.9 \mathrm{uU} / \mathrm{ml}$ on 2 days before starvation to $12.4 \pm 1.8 \mathrm{uU} / \mathrm{ml}$ after $24 \mathrm{hr}$ of fasting $(P<0.005)$ and remained low for the duration of the 7-day fasting period. The mean maternal arterial glucagon concentration in the fed state was $112 \pm 20 \mathrm{pg} / \mathrm{ml}$ and did not change significantly throughout the 7 days of maternal fasting.

Fetal arterial plasma glucose was much lower than maternal levels (mean $18.4 \pm 1.1 \mathrm{mg} / 100 \mathrm{ml}$ plasma $\mathrm{H}_{2} \mathrm{O}$ in the fed state), decreased to $12.1 \pm 1.4 \mathrm{mg} / 100 \mathrm{ml}$ after $24 \mathrm{hr}$ of fasting $(P<$ 0.05 ) and did not change significantly after the 1st day of fasting. The whole blood fructose concentration in the fetal artery was high in the fed state $(71.7 \pm .11 .5 \mathrm{mg} / 100 \mathrm{ml}$, mean 2 days before fasting) and fell quickly during starvation $(34.2 \pm 3.4 \mathrm{mg} / 100 \mathrm{ml}$ after $48 \mathrm{hr}$ ). The fructose concentration did not change further for the duration of the fasting period. The fetal arterial insulin concentration was lower than the maternal $(19.4 \pm 1.0 \mathrm{uU} / \mathrm{ml}$ in the fed state and did not fall dramatically after fasting as the mother did. After $24 \mathrm{hr}$ of fasting, the fetal insulin was $15.0 \pm 1.5 \mathrm{uU} / \mathrm{ml}$ $(P<0.005)$ and remained low throughout the fast. The umbilical venous-arterial differences of insulin were statistically different from 0 in both fed (mean $-1.4 \pm 0.3 \mathrm{uU} / \mathrm{ml} ; P<0.005$ ) and fasted state (mean $-1.4 \pm 0.5 \mathrm{uU} / \mathrm{ml} ; P<0.02$ ), with the fetal artery greater than the umbilical vein in 25 of 28 measurements. The fetal arterial concentration of glucagon was lower than in the ewe $(32 \pm 7 \mathrm{pg} / \mathrm{ml})$ and also did not change significantly during starvation.

There was a good correlation of the plasma glucose and insulin concentrations for both the fetus and the ewe. Analysis of pooled fetal and maternal regression lines for insulin-glucose relationships reveals no difference in the slope (maternal 0.48 , fetal 0.48 ), but a statistically significant difference in the $y$ intercept (maternal 7.70, fetal 8.65, $P<0.005$ ), with the fetal curve shifted to the left.

The excellent correlation between plasma glucose and insulin concentration throughout the fed and fasted periods suggests that the decrease in fetal plasma glucose and the decreased utilization of exogenous glucose by the fetus is mediated by fetal insulin level. Although the response of insulin to the change in glucose in the fetus is the same as in the mother, the threshold is set at a lower glucose concentration in the fetus. The data in this study would suggest that glucagon is not an important regulator of fetal metabolism during maternal starvation because there was no significant change in the glucagon concentration in the fetus throughout the study.

\section{Speculation}

Fetal growth and metabolism appear to be influenced by both substrate availability from the mother and fetal hormonal mechanisms. The role of alanine and the possibility of altering fetal growth by manipulating substrate availability need to be investigated to further understand the fetal metabolic response to maternal nutritional deprivation.

Very little is known about the effect of maternal starvation on the fetus. There is ample evidence that inadequate nutrition of the mother reduces the rate of fetal growth. Although this evidence implies that fetal metabolism (and fetal growth) changes in response to maternal nutrition, the nature of the response and the mechanisms that evoke it are unknown. Previous studies by Bassett and Madill (3), Simmons et al. (23), and Schreiner et al. (20) have shown that the sheep fetus undergoes dramatic metabolic adaptation when stressed by maternal fasting. Within $48 \mathrm{hr}$ of maternal fasting, both the maternal and fetal glucose concentrations decrease rapidly, resulting in decreased supply of glucose from the ewe to the fetus and decreased utilization of transplacentally acquired glucose by the fetus. Previous studies by Schreiner et al. (20) have shown that the umbilical glucose/oxygen quotient significantly decreases during fasting such that, in the fasted state, umbilical uptake of glucose can account for a maximum of $30 \%$ of fetal oxidative metabolism. Studies by Simmons et al. (23) and Schreiner et al. (20) have shown that urea production by the fetus approximately doubles during maternal starvation so that by 72 $\mathrm{hr}$ of fasting the fetus may derive as much as $40-50 \%$ of oxidative requirements from the catabolism of amino acids. Burd et al. (6) have shown that transplacentally acquired lactate may account for as much as $25 \%$ of oxidative metabolism in the fetus, and Schreiner et al. (20) found no significant difference in lactate/oxygen quotient to the fetus when the mother was fed or fasted. The possibility of increased umbilical uptake of other substrates for catabolism and growth have also been investigated. It would seem in the fetal sheep that acetoacetate, betahydroxybutyrate $(17,20)$, long chain free fatty acids $(15,20)$ and fructose $(20)$ are not taken up by the fetus in significant quantities when the ewe is fed or during severe maternal starvation. Therefore, it would seem that in the fetal sheep the metabolic adaptations of the human adult of increasing availability of ketones and free fatty acids for oxidative metabolism are not present.

Thus, the sheep fetus adapts to maternal starvation by decreasing its oxidative requirement for transplacentally acquired glucose 
by approximately one-half, increasing its amino acid catabolism by approximately $100 \%$ and maintaining oxidative catabolism of lactate at approximately the same level as during maternal feeding.

The major factors controlling these metabolic adaptations of the fetus during maternal starvation have not been investigated previously except during short-term (48 hr) starvation (3). The purpose of this study is to investigate the changes of plasma insulin and glucagon concentrations in relation to carbohydrate concentrations during the fed state and severe maternal fasting.

\section{MATERIALS AND METHODS}

\section{SURGERY AND CARE OF ANIMALS}

Five ewes of mixed western breed, 90-130 days of gestation were studied. The animals were starved for $48 \mathrm{hr}$ and water was withheld for $24 \mathrm{hr}$ before anesthesia. Surgical anesthesia consisted of approximately $10 \mathrm{ml}$ sodium pentobarbital $(50 \mathrm{mg} / \mathrm{ml})$ administered via the jugular vein and $20 \mathrm{mg}$ pontocaine hydrochloride injected intrathecally. Sterile physiologic saline was administered intravenously throughout the surgery, and oxygen and pentobarbital were given as needed.

A $30 \mathrm{~cm}$ incision in the ewe's abdomen and a $3-5 \mathrm{~cm}$ incision in the uterus were made. Polyvinyl catheters were placed in the umbilical vein and fetal femoral artery. The uterine membranes were then ligated with a 3-0 silk tie and the uterine wall closed with 3-0 silk sutures.

Sodium ampicillin, $500 \mathrm{mg}$, was injected intraamniotically to prevent infection. The catheters were filled with heparinized saline ( $35 \mathrm{U} / \mathrm{ml}$ ), plugged, and tunneled under the ewe's skin to a small puncture in her flank. A polyvinyl catheter was inserted into the maternal femoral artery and tunneled subcutaneously to the same puncture in the ewe's flank. All catheters were kept in a small plastic pouch fixed to the mother's flank.

After surgery, the animals were returned to special cages and were given water and food ad libitum. All animals were eating and all but one were standing within $6 \mathrm{hr}$ after surgery. Streptomycin sulfate $(0.5 \mathrm{~g})$ and potassium penicillin-G $(500,000 \mathrm{IU})$ were injected im daily for 3 days. The animals were allowed to recover $3-5$ days after surgery. The animals were fed alfalfa hay and Ralston Purina Omalene Horse Ration (St. Louis, MO) (crude protein not less than $10 \%$, crude fat not less than $2 \%$, crude fiber not more than $9 \%$, and approximately $50 \%$ carbohydrate).

All catheters were irrigated daily with heparinized saline to insure patency. After a minimum of 3 days recovery, blood samples were drawn each morning simultaneously from the maternal femoral artery $(4.5 \mathrm{ml})$, fetal femoral artery $(4.5 \mathrm{ml})$, and fetal umbilical vein $(4.5 \mathrm{ml})$. Total starvation was begun after blood samples had been drawn on the 3rd morning, but water was given ad libitum. The study was continued until the 8th day of starvation unless delivery, catheter failure or fetal death intervened.

\section{CHEMICAL ANALYSES}

Plasma glucose was measured by the glucose oxidase technique using a Beckman Glucose Analyzer (Fullerton, CA). All plasma glucose values were converted to $\mathrm{mg} / 100 \mathrm{ml}$ plasma water by utilizing the following equation:

mg glucose $/ 100 \mathrm{ml}$ plasma

$$
\text { 1-protein }(\mathrm{g} / \mathrm{ml} \text { plasma })
$$

$$
=\mathrm{mg} \text { glucose } / 100 \mathrm{ml} \text { plasma water }
$$

Whole blood fructose was determined according to Yaphe and Arsenault (25). Total protein was determined on plasma samples using an American Optical temperature compensated hand refractometer (Buffalo, NY).

Insulin was measured by radioimmunoassay according to the method of Heding (14). The pork insulin was generously supplied by Mary Root (Eli Lilly Laboratories, Indianapolis, IN). The sensitivity of the insulin assay in this laboratory is $0.5-200 \mathrm{uU} / \mathrm{ml}$ with a precision of $\pm 15 \%$ at a concentration of $0.5-20 \mathrm{uU} / \mathrm{ml}$. Glucagon assay was measured with the $30-\mathrm{K}$ antibody (Roger Unger, University of Texas Southwestern Medical School, Dallas, TX) purchased from Nuclear Medical Laboratories (Dallas, TX) (11). Blood specimens were collected in Trasylol and separated at $4^{\circ} \mathrm{C}$, then frozen at $-40^{\circ} \mathrm{C}$ until determination. The sensitivity of this assay in this laboratory is $25-1000 \mathrm{pg} / \mathrm{ml}$ with a precision of $\pm 15 \%$ in the $25-150 \mathrm{pg} / \mathrm{ml}$ range.

\section{STATISTICAL ANALYSIS}

The values are reported as the mean \pm SEM. The mean values for the data obtained during the 2 days before starvation was instituted were used for the control data. Differences between means were analyzed by the paired $t$ test. Standard regression analysis was used for correlations between substrates and hormones. Straight line regressions analyzing insulin-glucose relationships were calculated using the method of least squares. Composite maternal and fetal equations were calculated according to Brownlee (5), i.e., weighting each slope by the sum of squares of deviations of the abscissa values from their mean. Pooled intercepts were obtained using the pooled estimate of the slope, the mean of the ordinate, and the mean of the abscissa values.

\section{RESULTS}

Two animals were studied for 6 days of starvation, two for 7 days and one for 8 days of starvation. All fetuses were delivered by elective cesarean section at 127-137 days of gestational age. One fetus was dead at the time of cesarean section which was performed $24 \mathrm{hr}$ after the last sampling time. At the time of the last sampling $\mathrm{pH}, \mathrm{pCO}_{2}$ and $\mathrm{pO}_{2}$ of the fetus were normal.

\section{MATERNAL}

The mean maternal arterial plasma glucose concentration (Fig. 1) before starvation $\left(73.4 \pm 31.1(\mathrm{SEM}) \mathrm{mg} / 100 \mathrm{ml}\right.$ plasma $\mathrm{H}_{2} \mathrm{O}$ ) fell to $54.8 \pm 5.2 \mathrm{mg} / 100 \mathrm{ml}(P<0.01)$ after $24 \mathrm{hr}$ of fasting and to $37.5 \pm 1.6 \mathrm{mg} / 100 \mathrm{ml}(P<0.001)$ by $72 \mathrm{hr}$ of fasting. The maternal arterial fructose concentration was low in both the fed $(2.9 \pm 0.4 \mathrm{mg} / 100 \mathrm{ml})$ and fasted states $(1.8 \pm 0.5 \mathrm{mg} / 100 \mathrm{ml}$, day 3). The maternal arterial insulin concentration fell early in fasting from a mean of $27.9 \pm 3.9 \mathrm{uU} / \mathrm{ml}$ on 2 days before starvation to $12.4 \pm 1.8 \mathrm{uU} / \mathrm{ml}$ after $24 \mathrm{hr}$ of fasting $(P<0.005)$ and remained low for the duration of the 7-day fasting period. The mean maternal arterial glucagon concentration in the fed state was 112 $\pm 20 \mathrm{pg} / \mathrm{ml}$ and did not change significantly throughout the 7 days of maternal fasting.

\section{FETAL}

Fetal arterial plasma glucose (Fig 2) was much lower than maternal levels (mean $18.4 \pm 1.1 \mathrm{mg} / 100 \mathrm{ml}$ plasma $\mathrm{H}_{2} \mathrm{O}$ in the fed state), decreased to $12.1 \pm 1.4 \mathrm{mg} / 100 \mathrm{ml}$ after $24 \mathrm{hr}$ of fasting $(P<0.05)$ and did not change significantly after the lst day of fasting. The whole blood fructose concentration in the fetal artery was high in the fed state $(71.7 \pm 11.5 \mathrm{mg} / 100 \mathrm{ml}$, mean 2 days before fasting) and fell quickly during starvation (34.2 $\pm 3.4 \mathrm{mg}$ / $100 \mathrm{ml}$ after $48 \mathrm{hr}$ ). The fructose concentration did not change further for the duration of the fasting period. The fetal arterial insulin concentration was lower than the maternal $(19.4 \pm 1.0$ $\mathrm{uU} / \mathrm{ml}$ ) in the fed state and did not fall dramatically after fasting as the mother did. At $24 \mathrm{hr}$ of fasting, the fetal arterial insulin was $15.0 \pm 1.5 \mathrm{uU} / \mathrm{ml}(P<0.005)$ and remained low throughout the fast. The umbilical venous-arterial differences of insulin (Fig. 3) were statistically different from 0 by the paired $t$ test in both fed (mean $-1.4 \pm 0.3 \mathrm{uU} / \mathrm{ml}, P<0.005$ ) and fasted state (mean $1.4 \pm 0.5 \mathrm{uU} / \mathrm{ml}, P<0.02$ ), with the fetal artery greater than the umbilical vein in 25 of 28 measurements. The fetal arterial con- 

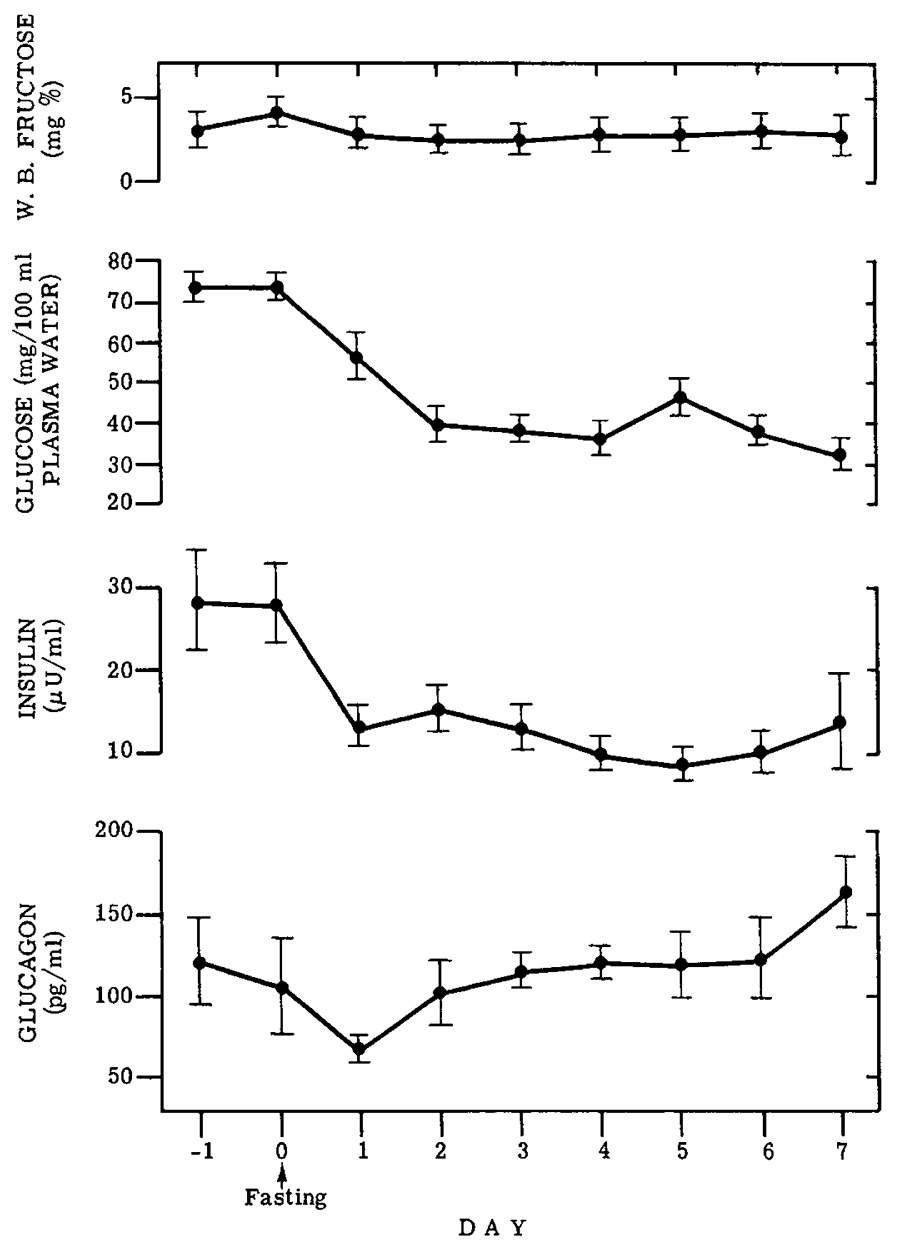

Fig. 1. Maternal arterial fructose, glucose, insulin, and glucagon concentrations $( \pm$ SEM) in the fed and fasted states.

centration of glucagon was lower than in the ewe $(32 \pm 7 \mathrm{pg} / \mathrm{ml})$ and also did not change significantly during starvation, although the values on the $3 \mathrm{rd}$ day of fasting were close to statistical significance. The umbilical venous-arterial glucagon concentration was not statistically different than 0 .

\section{CARBOHYDRATE-HORMONAL RELATIONSHIPS}

The correlations of the plasma glucose and insulin concentrations for all animals are seen in Figures 4 and 5. There was a good correlation for both the fetus (Fig. 4) and the ewe (Fig. 5). Figure 6 shows the fetal and maternal insulin glucose regression line for sheep 2. Analysis of pooled fetal and maternal regression lines for insulin-glucose relationships reveal no difference in the slope (maternal 0.48, fetal 0.48), but a statistically significant difference in the $y$ intercept (maternal -7.70 , fetal $8.65, P<0.005$ ), with the fetal curve shifted to the left (Table 1). When insulin was correlated with the sum of the fructose and plasma glucose concentrations, the coefficient was unchanged for the ewe and decreased $(0.53$ vs. 0.33$)$ in the fetus.

There was no significant correlation between the maternal glucagon concentration and plasma glucose concentration or between the fetal glucagon concentration and fetal plasma glucose. There was also no significant correlation for glucagon and the sum of the plasma glucose and plasma fructose concentration in the fetus.

\section{DISCUSSION}

The major factors controlling the metabolic adaptation of the human adult during starvation appear to be: 1) insulin concentration, 2) glucagon concentration, 3) plasma ketone concentration, and 4) plasma alanine concentration $(7,8,19)$. During the initial phase of starvation, lasting approximately 1 wk in the human adult, the major hormonal control appears to be insulin, regulating peripheral lipolysis and proteolysis and decreasing glucose uptake in the periphery. Glucagon appears to act mainly at the liver, stimulating glycogen release and gluconeogenesis by increasing hepatic uptake of alanine. During the second phase or the prolonged phase of starvation in the human adult, the decreased plasma alanine level appears to be the regulating factor for decreasing hepatic gluconeogenesis. Because insulin levels remain
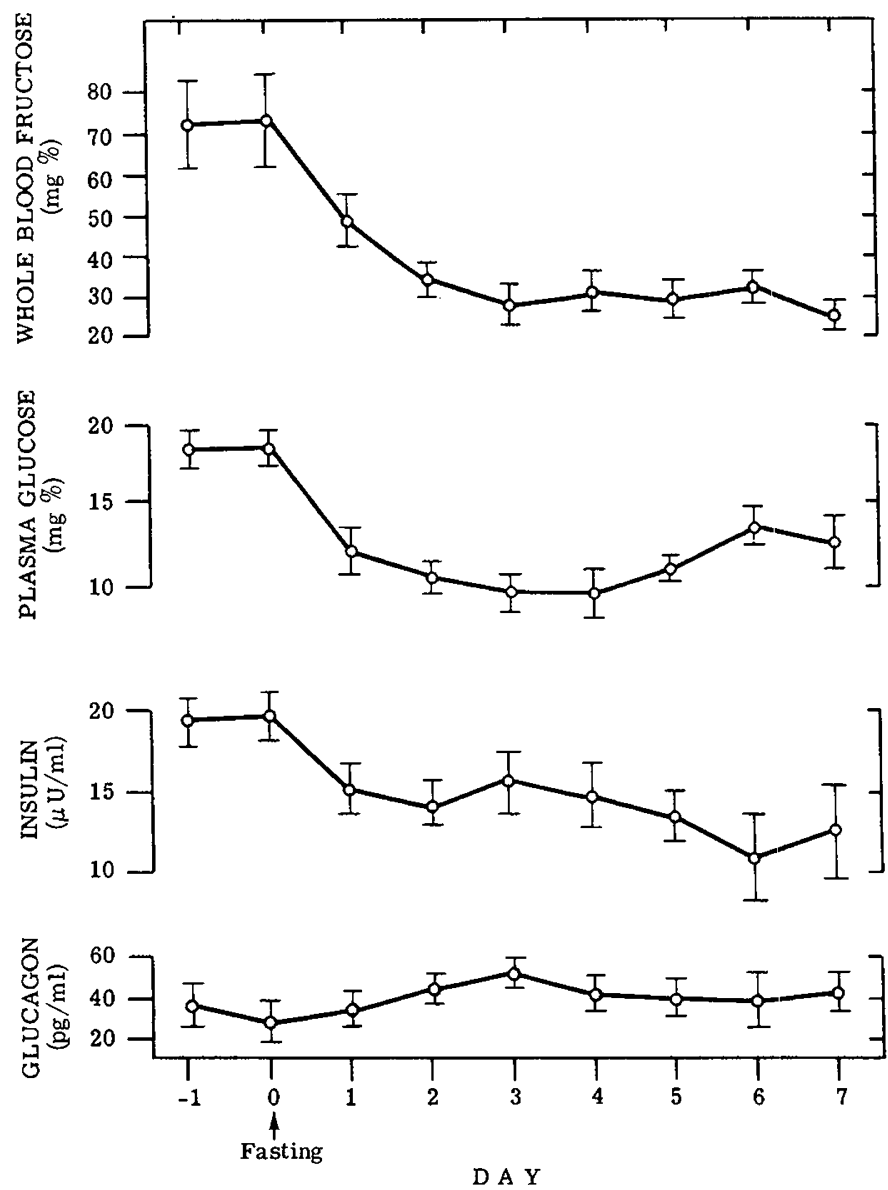

Fig. 2. Fetal arterial fructose, glucose, insulin, and glucagon concentrations $( \pm$ SEM $)$ in the fed and fasted states.

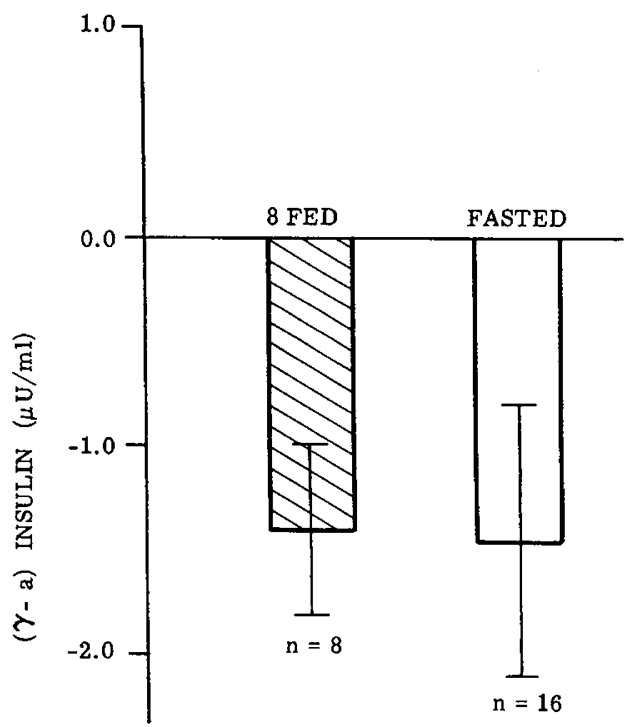

Fig. 3. Umbilical venous-arterial $(\gamma-a)$ insulin concentration $( \pm$ SEM) in the fed and fasted states. 


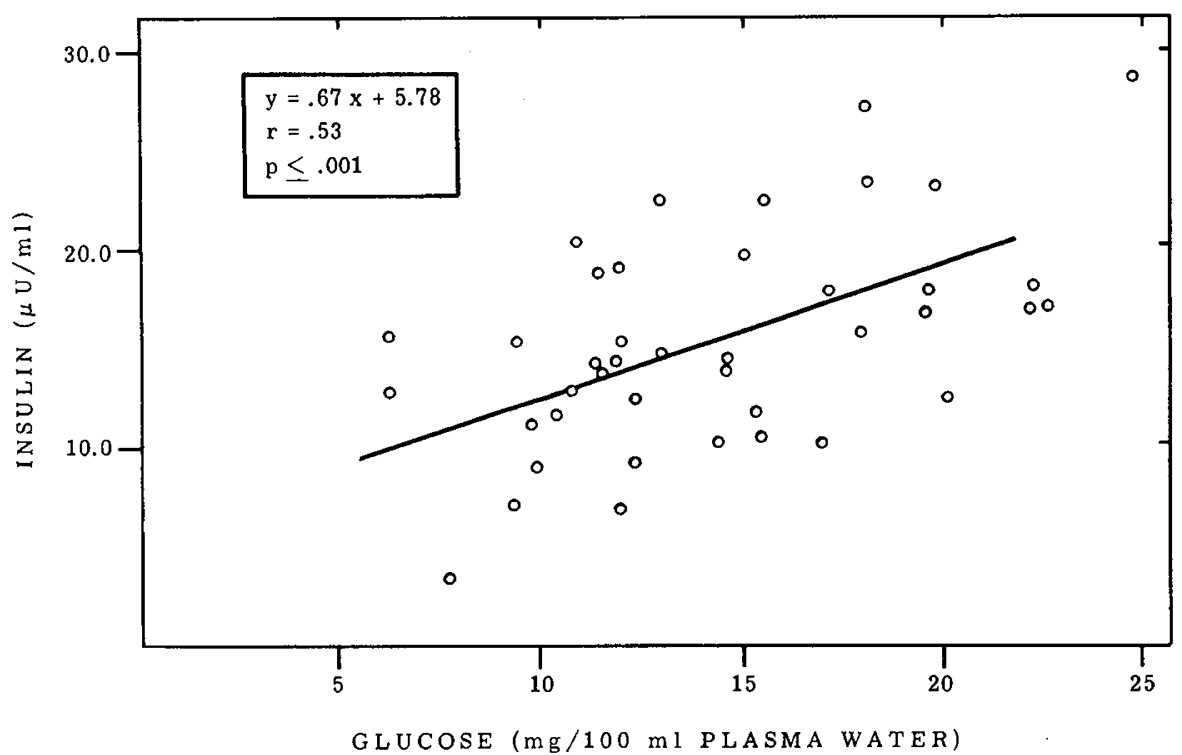

Fig. 4. Correlation of fetal arterial plasma glucose concentration and fetal arterial insulin concentration.

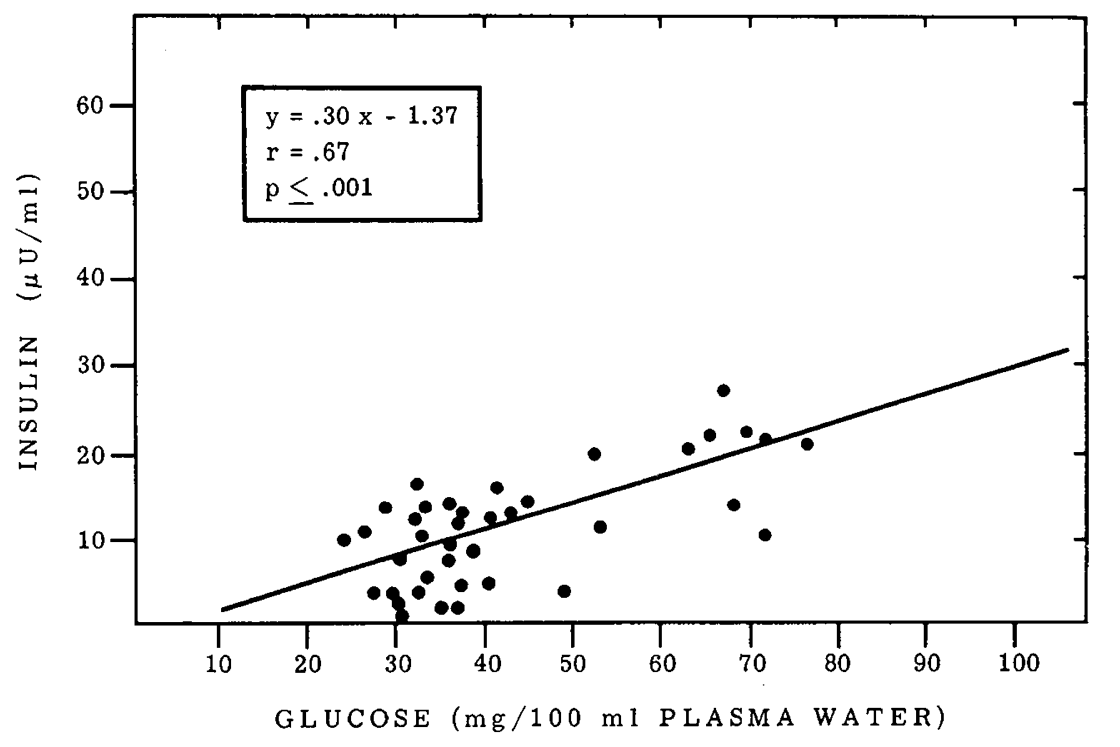

Fig. 5. Correlation of maternal arterial plasma glucose concentration and maternal arterial insulin concentration.

reduced and glucagon concentrations remain elevated throughout the period of prolonged starvation, it would seem that these hormones are not the major regulators of decreased gluconeogenesis during prolonged human adult starvation. Sherwin et al. (22) has suggested that increased ketone concentration during prolonged starvation is the stimulus to the decrease of alanine production at the muscles. Thus, ketones would appear to not only be the major substrate for the brain during prolonged starvation in the human adult, but also be the controlling factor decreasing amino acid metabolism by reducing the release of alanine in the muscles.

The fetal pancreas is capable of producing insulin in response to glucose as early as 50 days of gestation in the sheep, and insulin can be detected in the fetal plasma throughout the remaining duration of pregnancy (21). It would seem from these studies as well as those of Bassett and Madill (3) that the fall in glucose concentration in the first $24-48 \mathrm{hr}$ in the sheep fetus after maternal starvation results in a decrease in plasma insulin concentration. In both studies, the decrease in the fetal plasma insulin concentration was less than that in the mother. In this study, the glucose concentration and the insulin concentration reached a steady state within 2-3 days after maternal fasting and remained constant throughout the duration of fasting. The excellent correlation between plasma glucose and insulin concentration throughout the fed and fasted periods suggests that the decrease in fetal plasma glucose and the decreased utilization of exogenous glucose by the fetus is mediated by fetal insulin level. However, as seen in Figure 6 and Table 1, the intercepts of the correlation of plasma insulin and plasma glucose concentration are significantly different in the fetus and the mother. The slopes of the regression line are not statistically different. This data is similar to that reported by Philipps et al. (18) and suggests that, although the response of insulin to the change in glucose in the fetus is the same as the mother, the threshold is set at a lower glucose concentration in the fetus. Because the fetal sheep has a very high concentration of fructose, it is possible that the fructose concentration in some way also regulates insulin levels. However, the authors found no improvement in the regression analysis when insulin was plotted against the sum of glucose and fructose compared to the plot against glucose only. In addition, Philipps et al. (18) could not relate the variation of plasma insulin to changes in fructose concentration even when the glucose concentration was kept constant. Thus, it would seem that plasma fructose concentration in the sheep fetus does not significantly influence fetal plasma 
insulin concentration. In addition, as mentioned above, the evidence would suggest that fructose is not a significant oxidative metabolite in the sheep fetus. Although fructose concentration in the fetus does not appear to regulate fetal insulin concentration, there is significant evidence that infusion of fructose into the fetus will result in an increase in the fetal insulin concentration, although to a lesser degree than infusion of a similar quantity of glucose $(2,18)$.

The umbilical venous-arterial difference of insulin suggests that insulin is degraded in the placenta. Assuming a mean umbilical venous $(\gamma)$-arterial (a) difference of $1.5 \mathrm{uU} / \mathrm{ml}$ (Fig. 3) one can calculate the placental uptake $(\dot{\mathrm{Q}})$ of insulin from the Fick principle: $\dot{Q}=\mathrm{UBF}(\gamma-\mathrm{a})$. Assuming an umbilical blood flow (UBF) of $200 \mathrm{ml} / \mathrm{kg} / \mathrm{min}(16): \mathrm{Q}=200 \mathrm{ml} / \mathrm{kg} / \mathrm{min}(1.5 \mathrm{uU} / \mathrm{ml})=300$ $\mathrm{uU} / \mathrm{kg} / \mathrm{min}=0.3 \mathrm{mU} / \mathrm{kg} / \mathrm{min}$. This value is the same as the adult sheep insulin secretion rate determined by Trenkle (24) $(0.3 \mathrm{mU} /$ $\mathrm{kg} / \mathrm{min}$ ) and twice that reported by Brockman and Bergman (4) $(0.15 \mathrm{mU} / \mathrm{kg} / \mathrm{min})$. Brockman and Bergman (4) found that the hepatic and renal removal of insulin was approximately $85 \%$ of the secretion rate. The placenta assumes many of the functions of these two organs in the fetus and might be the major site of insulin removal. This is supported by the finding of Freinkel and Goodner of insulinase activity in the placenta (13).

The role of glucagon in regulating fetal metabolism in response to maternal starvation has not been studied. As with insulin, glucagon has been identified in the fetal pancreas from early in gestation and the evidence would suggest that glucagon is not transferred across the placenta $(9,12)$. Chez et al. (9) have shown in the normal monkey pregnancy, fetal hypoglycemia, hyperglycemia, and hyperalanemia are not associated with changes in fetal plasma glucagon concentration. Epstein et al. (10) found no increase in fetal glucagon in the rhesus monkey made glucoseintolerant with streptozotocin. Fiser et al. (12) found no increase in glucagon concentration in response to glucose infusion in the fetus. The concentration of the glucagon in the fetal sheep as well

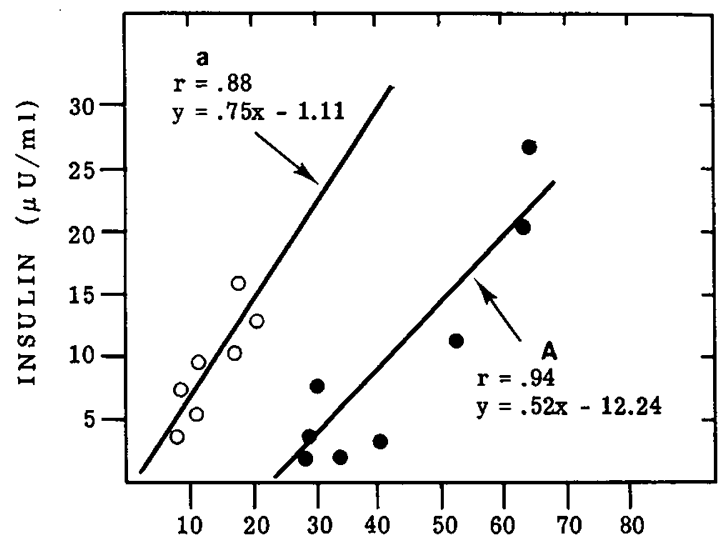

GLUCOSE (mg/100ml PLASMA WATER)

Fig. 6. Correlations of arterial plasma glucose concentration and insulin concentration for sheep 2 in the fetus (open circles) and in the ewe (closed circles). as in monkey and man is significantly less than in the maternal blood. The data in this study would suggest that glucagon is not an important regulator of fetal metabolism during maternal starvation because there was no significant change in the glucagon concentration in the fetus throughout the study. In addition, there was no significant correlation between the plasma glucose concentration or the plasma glucose plus fructose concentration and fetal plasma glucagon concentration.

The lack of increase in the plasma glucagon concentration in the ewe is quite different than that of starvation in the human adult. Bassett (1) has studied plasma glucagon concentration in nonpregnant sheep in relation to nutrition and found that the plasma glucagon concentration increased from approximately $175-400 \mathrm{pg} / \mathrm{ml}$ with feeding, but that the value decreased to prefeeding levels by approximately $16 \mathrm{hr}$ after a feeding and did not change significantly with starvation of four days' duration. Thus, they found changes in glucagon concentration only acutely associated with feeding periods. The increase in glucagon acutely with feeding in the sheep is quite consistent with ruminant metabolism in that gluconeogenesis is very active in the sheep immediately after feeding. Thus, in nonpregnant sheep, it would seem that glucagon does not increase with prolonged starvation as it does with the human adult.

\section{REFERENCES AND NOTES}

1. Bassett, J. M.: Plasma glucagon concentrations in sheep: their regulation and relation to concentrations of insulin and growth hormone. Aust. J. Biol. Sci., 25: 1277 (1972).

2. Bassett, J. M., and Madill, D.: Influence of prolonged glucose infusions on plasma insulin and growth hormone concentrations of foetal lambs. J. Endocrinol., 62: 299 (1974).

3. Bassett, J. M., and Madill, D.: The influence of maternal nutrition on plasma hormone and metabolite concentrations of foetal lambs. J. Endocrinol., 61: 465 (1974).

4. Brockman, R. P., and Bergman, E. N.: Quantitative aspects of insulin secretion and its' hepatic and renal removal in sheep. Am. J. Physiol., 229: 1338 (1975).

5. Brownlee, K. A.: In: Statistical Theory and Methodology (John Wiley and Sons, New York, 1969)

6. Burd, L. I., Jones, M. D., Jr., Simmons, M. A., Makowski, E. L., Meschia, G. and Battaglia, F. C.: Placental production and foetal utilisation of lactate and pyruvate. Nature, 254: 710 (1975).

7. Cahill, G. F., Jr.: Starvation in man. N. Engl. J. Med., 282: 668 (1970)

8. Cahill, G. F., Jr., Herrera, M. G., Morgan, A. P., Soeldner, J. S., Steinke, J., Levy, P. O., Reichard, G. A., and Kipnis, D. M.: Hormone-fuel interrelationships during fasting. J. Clin. Invest., 45: 1751 (1966).

9. Chez, R. A., Mintz, D. H., Epstein, M. F., Fleischman, A. R., Oakes, G. K., and Hutchinson, D. L.: Glucagon metabolism in nonhuman primate pregnancy. Am. J. Obstet. Gynecol., 120: 690 (1974).

10. Epstein, M., Chez, R. A., Oakes, G. K., and Mintz, D. H.: Fetal pancreatic glucagon responses in glucose-intolerant nonhuman primate pregnancy. Am. J. Obstet. Gynecol., 127: 268 (1977).

11. Faloona, G., and Unger, R.: Glucagon. In: B. Jaffe and H. Behrman: Methods of Hormone Radioimmunoassay (Academic Press, New York, 1974) p. 317.

12. Fiser, R. H., Jr., Erenberg, A., Sperling, M. A., Oh, W., and Fisher, D. A. Insulin-glucagon substrate interrelations in the fetal sheep. Pediatr. Res., 8: 951 (1974).

13. Freinkel, N., and Goodner, C. J.: Carbohydrate metabolism in pregnancy, I. The metabolism of insulin by human placental tissue. J. Clin. Invest., 39: 116 (1960).

14. Heding, L. G.: Determination of total serum insulin (IRI) in insulin-treated diabetic patients. Diabetologia, 8: 260 (1972).

15. James, E., Meschia, G., and Battaglia, F. C.: A-V differences of free fatty acids and glycerol in the ovine umbilical circulation (35999). Proc. Soc. Exp. Biol. Med., 138: 823 (1971).

Table 1. Fetal-maternal insulin-glucose relationships

\begin{tabular}{|c|c|c|c|c|c|c|c|c|}
\hline Animal & $\mathrm{n}^{1}$ & Slope & $\begin{array}{c}\text { Fetal } \\
\text { intercept }\end{array}$ & $\mathbf{r}$ & $\mathrm{n}^{*}$ & Slope & $\begin{array}{l}\text { Maternal } \\
\text { intercept }\end{array}$ & $\mathbf{r}$ \\
\hline 1 & 8 & 0.71 & -2.81 & 0.76 & 9 & 0.25 & -5.82 & 0.90 \\
\hline $2^{2}$ & 7 & 0.75 & -1.11 & 0.88 & 7 & 0.52 & -12.24 & 0.94 \\
\hline 3 & 7 & 0.93 & +2.85 & 0.72 & 6 & 1.18 & -37.64 & 0.92 \\
\hline 4 & 9 & 0.19 & +14.30 & 0.38 & 9 & 0.24 & +3.46 & 0.88 \\
\hline 5 & 9 & 0.95 & +6.05 & 0.66 & 9 & 0.23 & +5.73 & 0.87 \\
\hline Pooled means & & 0.48 & +8.65 & $0.53(P<0.001)$ & & 0.48 & -7.70 & $0.67(P<0.001)$ \\
\hline
\end{tabular}

${ }^{1}$ Number of observations.

${ }^{2}$ Animal presented in Figure 6. 
16. Meschia, G., Cotter, J. R., Makowski, E. L., and Barron, D. H.: Simultaneous measurement of uterine and umbilical blood flows and oxygen uptakes. Q. J. Exp. Physiol., 52: 1 (1967).

17. Morriss, F. H., Boyd, R. D. H., Makowski, E. L., Meschia, G., and Battaglia, F. C.: Umbilical V-A differences of acetoacetate and $\beta$-hydroxybutyrate in fed and starved ewes (37915). Proc. Soc. Exp. Biol. Med., 145: 879 (1974).

18. Philipps, A. F., Carson, B. S., Meschia, G., and Battaglia, F. C.: Insulin secretion in fetal and newborn sheep. Am. J. Physiol. (in press).

19. Saudek, C. D., and Felig, P.: The metabolic events of starvation. Am. J. Med. 60: 117 (1976)

20. Schreiner, R. L., Burd, L. I., Jones, M. D., Jr., Lemons, J. A., Sheldon, R. E., Simmons, M. A., Battaglia, F. C., and Meschia, G.: Fetal metabolism in fasting sheep. In: L. Longo: Circulation in the Fetus and Newborn (Garland Publishing, Inc., New York)

21. Shelley, H. J., and Bassett, J. M.: Control of carbohydrate metabolism in the fetus and newborn. Br. Med. Bull., 31: 37 (1975).

22. Sherwin, R. S., Hendler, R. G., and Felig, P.: Effect of ketone infusions on amino acid and nitrogen metabolism in man. J. Clin. Invest., 55: 1382 (1975)

23. Simmons, M. A., Meschia, G., Makowski, E. L., and Battaglia, F. C.: Fetal metabolic response to maternal starvation. Pediatr. Res., 8: 830 (1974).

Copyright (c) 1980 International Pediatric Research Foundation, Inc $0031-3998 / 80 / 1402-0103 \$ 02.00 / 0$
24. Trenkle, A.: Postprandial changes in insulin secretion rates in sheep. J. Nutr., 101: 1099 (1971)

25. Yaphe, W., and Arsenault, G. P.: Improved resorcinol reagent for the determination of fructose, and of 3,6-anydrogalactose in polysaccharides. Anal. Biochem., 13: 143 (1965)

26. Dr. Schreiner is Associate Professor of Pediatrics.

27. Ms. Nolen is Research Technician.

28. Ms. Bonderman is Research Technician.

29. Dr. Moorehead is Research Technician.

30. Dr. Gresham is Professor of Pediatrics.

31. Dr. Lemons is Associate Professor of Pediatrics.

32. Dr. Escobedo is Assistant Professor of Pediatrics.

33. This research was supported by grants from James Whitcomb Riley Memorial Association (76-9, 77-3, and 78-9) and Diabetes Center Gran ( $\#$ P60AM20542-SRC).

34. Requests for reprints should be addressed to: Richard L. Schreiner, M. D., Department of Pediatrics, Indiana University School of Medicine, 1100 West Michigan Street, Indianapolis, IN 46223, USA.

35. Received for publication October 10, 1978

36. Accepted for publication March 2,1979. 